\title{
THE EFFECT OF PARTICLE SIZE ON BIOAVAILABILITY IN CYCLOSPORINE PREPARATIONS BASED ON SUBMICRON DISPERSIONS
}

\author{
Aleš Vrána ${ }^{a}$, Tomáš Andrýsek \\ a Department of Immunotherapeutic Products, IVAX-CR, a.s., \\ e-mail: ales_vrana@ivax-cr.com \\ ${ }^{b}$ Department of Biopharmacy and Pharmacokinetics, IVAX-CR, a.s., Ostravská 29, 74770 Opava 9, Czech Republic
}

Received: October 18, 2001

Key words: Cyclosporine A / Bioavailability / Particle Size

The effect of particle size on bioavailability of 9 different formulations with cyclosporine A was studied. A common feature of all the formulations was the ability to form submicron dispersions under dilution. The composition of individual formulations was chosen in such a way that they were based on same or similar excipients. For each formulation, pharmacokinetic study was carried out in beagle dogs. On groups of 10 dogs, the average AUC was evaluated. Particle size of formulations under dilution in water was measured by laser scattering method. According to the results of particle size measurement, the formulations were sorted out into groups of similar particle size distribution by use of two methods of multivariate statistical analysis. The average AUC within groups and between-groups was compared, and the effect of particle size on bioavailability was evaluated.

\section{INTRODUCTION}

Cyclosporine A, an immunosuppressive drug, was introduced into the therapeutic practice in 80's. As a poorly water-soluble compound, it was originally formulated into a lipophilic medium providing crude emulsion after dilution with water. Since that time, a lot of effort was paid to the improvement of cyclosporine bioavailability. One of the first improvements, reported either for co-administration of long- and medium-chain triglycerides or reported for sucrose laurate, were associated with formation of mixed micelles in the gut or small intestine $(1,2)$. Further approaches included formulations based on formation of liposomes $(3,4)$, nanoparticles, or liquid crystals (5). The common feature of these approaches was to control the creation of some kind of dispersion in either the fluid for administration, or in stomach, or gut or small intestine. Therefore, self-establishing submicron dispersions were generally preferred for this purpose. After microemulsions or microemulsion preconcentrates were introduced in 90's, the size of particles has been considered an important and almost crucial factor affecting the bioavailability of cyclosporine A preparations which are based on the formation of submicron dispersions (6).

To verify such an assumption is not a simple task: once a formulation has a controlled size distribution independent from the conditions of administration (i.e., from dilution, mixing time and speed etc.), it can be changed only by a change of the ratio of individual excipients or by replacement of the excipients. Hence, any change of bioavailability can be attributed to the effect of a particular excipient rather than to the effect of particle size of the formulation. For this reason, we tried to prepare formulations which would differ in the size of particles that the formulations form after dilution by varying only the same or similar excipients. In this way, we obtained 9 different formulations in which the effect of excipients was minimized and the particle size of which ranged from 10 to $500 \mathrm{~nm}$.

Another problem is how to evaluate the particle size. Obviously, the use of one single parameter like the average particle diameter, hydrodynamic diameter, or aggregate molecular weight can be misleading not only because of not reflecting the particle shape, but also because of masking the information about particle size distribution. The approach used in this study was to compare the similarity or dissimilarity of particle size distribution by means of statistical methods for multivariate analysis. Two independent methods were used: the principal component analysis (PCA) and cluster analysis (CA). To evaluate the effect of particle size on bioavailability, the average AUC was compared for those formulations which showed significant difference in particle size distribution both by PCA and CA.

\section{METHODS}

\section{Materials}

All the formulations tested were prepared on laboratory scale equipment in laboratories of Department of Biopharmacy and Pharmacokinetics, IVAX-CR, a.s., Czech Republic. Excipients used in composition of individual formulations were commercially available materials of pharmaceutical grade. The quali-quantitative composition of all 9 formulations is listed in Table 1 . 


\section{Subjects}

Beagle dogs, males aged between 12-36 months of weight 9-15 kg were used in each pharmacokinetic study. The dogs were fed with a standard pellet diet in a quantity $300 \mathrm{~g}$ per day with water ad libitum.

\section{Pharmacokinetic studies}

Each individual formulation was administered with a dosing pipette in a form of pre-diluted dispersion as a single dose of $100 \mathrm{mg}$ cyclosporine A. The administration was preceded by $18 \mathrm{~h}$ fasting period. After administration, blood samples were taken in $0,1,2,3,5,8,12$, and 24 hour intervals. Samples were analysed for cyclosporine content by non-specific radioimmunoassay method. From the concentration - versus - time curves, area under the curve (0-24) was calculated.

\section{Blood collection}

Blood samples were taken from foreleg vein of the dogs into tubes with EDTA K3 $(1,5 \mathrm{mg} / \mathrm{ml})$. The samples were immediately frozen at $-20{ }^{\circ} \mathrm{C}$ and kept in a freezer until analysis.

\section{Cyclosporine A determination}

Non-specific RIA assay for cyclosporine A, IMMUNOTECH, Prague, Czech Republic, Cyclosporine RIA and its metabolites, Cat. \#1444 was used. $50 \mu \mathrm{l}$ of blood sample were extracted with $950 \mu \mathrm{l}$ of methanol. After centrifugation $\left(1600 \times \mathrm{g}, 5\right.$ minutes, $\left.5^{\circ} \mathrm{C}\right), 50 \mu \mathrm{l}$ of extracted samples, controls and standards were transferred into polystyrene tubes. $100 \mu \mathrm{l}$ of ${ }^{125} \mathrm{I}-\mathrm{CyA}$ and $50 \mu \mathrm{l}$ of polyclonal antibody was added. The reaction tubes were incubated 3 hours at $25^{\circ} \mathrm{C}$. $500 \mu$ of separating reagent was added and reaction tubes were incubated 1 hour at $5^{\circ} \mathrm{C}$. After centrifugation $(1600 \times \mathrm{g}$, 20 minutes, $5^{\circ} \mathrm{C}$ ) and decanting the supernatant, the bound radioactivity of calibrators, controls and samples were measured. All calibrators, controls and samples were made in duplicates. The radioactivity was measured using gamma scintillation counter MULTIGAMMA 1261 (LKB, Finland). The results were calculated using WiaCalc software (LKB, Finland). The calibration range of RIA (non-specific) method was $8-1680 \mathrm{ng} / \mathrm{ml}$. Functional sensitivity was calculated at about $8 \mathrm{ng} / \mathrm{ml}$. Within assay precision lied at $472 \mathrm{ng} / \mathrm{ml}-6,0 \%$, at $836 \mathrm{ng} / \mathrm{ml}$ $-4.2 \%$, Between assay precision at $347 \mathrm{ng} / \mathrm{ml}-5.7 \%$ at $754 \mathrm{ng} / \mathrm{ml}-5.6 \%$. The analysis were performed by Department of Nuclear Medicine at University Hospital in Ostrava. This laboratory participated in international External Quality Assessment (DGKC - Deutche Gesellschaft für Klinische Chemie, Ringversuch für Ciclosporin).

\section{Particle size determination}

Particle size distribution was measured by quasielastic light scattering method (QELS) using Ar-laser (Lexel Laser Inc., USA, $\lambda=514.5 \mathrm{~nm}$, output power $50 \mathrm{~mW})$ as a light source and the BI-9000 AT digital correlator (Brookhaven Instruments, USA) as a detector. The detector and light source arrangement was set up in angle $90^{\circ}$ by BI $200 \mathrm{SM}$ goniometer. The samples were prepared by dilution of concentrates with redistilled water at ratio 1:20 followed by standard homogenization in ultrasonic bath $(10 \mathrm{~min})$. All measurements were done at $25^{\circ} \mathrm{C}$.

The autocorrelation curves and the scattered light intensities were processed by Brookhaven software for dynamic light scattering. Particle size distribution spectra obtained were transformed to equal scales. All measurements were done by Department of Chemical Theory of Drugs, Faculty of Pharmacy, Commenius University, Bratislava, Slovak Republic.

\section{Software and Statistical methods:}

Pharmacokinetic parameters were calculated with WinNonlin 1.1 (Scientific Consulting Inc., USA). Their Multiple-range analysis, Two-sample analysis and Boxand -Whisker plots were done in Statgraphics, v.7.0. To resolve formulations into groups, principal component analysis method and cluster analysis method in S-Plus 2000 (MathSoft Inc., USA) were used. Bi-directional comparison of bioavailability versus particle size was performed: for pairs of formulations which were identified as substantially different from the particle distribution size point, two-sample comparison of AUC (0-24) was done. Vice versa, formulations identified as significantly different from the bioavailability point of view (having statistically significant difference in AUC found by multiple comparison method) were compared from the point of their particle size distribution.

\section{RESULTS}

\section{Pharmacokinetic studies}

The results of bioavailability studies in dogs are summarized in Table 2. The graphical analysis of the results is done by means of Box-and-Whisker plot (Figure 1). As can be seen from Figure 1, formulations L261 and L 267 appear to be significantly different from the point of their bioavailability in dogs. As possibly different can be identified also the pairs of formulations L267 - L269, L267 -L272, and L267 - L300. 
The effect of particle size on bioavailability in cyclosporine preparations based on submicron dispersions

Table 1. Qualitative and quantitative composition of tested formulations

\begin{tabular}{|c|c|c|c|c|c|c|c|c|c|}
\hline \multirow{2}{*}{ Components } & \multicolumn{9}{|c|}{ Formulations $\longrightarrow$} \\
\hline & L261 & L263 & L267 & L267.2 & L269 & L271 & L272 & L273 & L300 \\
\hline Cyclosporine A & $10.0 \%$ & $10.0 \%$ & $10.0 \%$ & $10.0 \%$ & $10.0 \%$ & $10.0 \%$ & $10.0 \%$ & $10.0 \%$ & $10.0 \%$ \\
\hline Cremophor RH 40 & $45.0 \%$ & $40.0 \%$ & & & $25.5 \%$ & $35.0 \%$ & $28.2 \%$ & $28.0 \%$ & $40.0 \%$ \\
\hline $\begin{array}{l}\text { Polysorbate Tween } \\
80\end{array}$ & $13.5 \%$ & $20.0 \%$ & & & & & & $22.0 \%$ & \\
\hline Oleic Acid & $31.5 \%$ & $10 \%$ & & $10.0 \%$ & & & & & \\
\hline $\begin{array}{l}\text { Diglyceryl } \\
\text { monooleate }\end{array}$ & & $20 \%$ & & & $9.5 \%$ & & $12.2 \%$ & & \\
\hline Oleyl Alcohol & & & $31.5 \%$ & $21.0 \%$ & $19.9 \%$ & $21.0 \%$ & $19.0 \%$ & $22.0 \%$ & \\
\hline $\begin{array}{l}\text { Polysorbate Tween } \\
20\end{array}$ & & & $13.0 \%$ & & & $17.0 \%$ & & & \\
\hline $\begin{array}{l}\text { Covitol } \\
\text { F 1000-2 }\end{array}$ & & & $0.5 \%$ & $0.5 \%$ & & & & & \\
\hline Nikkol HCO-40 & & & $45.0 \%$ & $40.0 \%$ & & & & & \\
\hline $\begin{array}{l}\text { Decaglyceryl } \\
\text { Monolaurate }\end{array}$ & & & & $8.5 \%$ & $16.0 \%$ & & $18.6 \%$ & & \\
\hline Propylene glycol & & & & & $20.0 \%$ & & $12.0 \%$ & & $10.0 \%$ \\
\hline $\begin{array}{l}\text { Decaglyceryl } \\
\text { Pentaoleate }\end{array}$ & & & & & & $17.0 \%$ & & & \\
\hline $\begin{array}{l}\text { Tocopheryl } \\
\text { linoleate }\end{array}$ & & & & & & & & $18.0 \%$ & \\
\hline $\begin{array}{l}\text { Glyceryl mo- } \\
\text { nolinoleate }\end{array}$ & & & & & & & & & $30.0 \%$ \\
\hline Ethanol & & & & & & & & & $10.0 \%$ \\
\hline Water & & & & $10 \%$ & & & & & \\
\hline
\end{tabular}

*) all concentrations listed are w/w concentrations

Table 2. Results of Bioavailability Studies (AUC (0-24)) for 9 Formulations in Dogs

\begin{tabular}{|c|c|c|c|c|c|c|c|c|c|}
\hline \multirow{2}{*}{$\begin{array}{l}\text { Subjects } \\
\text { (dogs) }\end{array}$} & \multicolumn{9}{|c|}{ Formulations } \\
\hline & \multicolumn{9}{|c|}{ AUC (0-24) $[\mu \mathrm{g} / \mathrm{l} / \mathrm{h}]$} \\
\hline & L261 & L263 & L267 & L267-2 & L269 & L271 & L272 & L273 & L300 \\
\hline 1 & 16747 & 9823 & 10558 & 14655 & 19886 & 9389 & 7131 & 11171 & 13442 \\
\hline 2 & 6268 & 10854 & 7754 & 13359 & 12045 & 16229 & 16797 & 13068 & 8960 \\
\hline 3 & 15416 & 14192 & 12651 & 15473 & 15890 & 10459 & 11531 & 9826 & 9869 \\
\hline 4 & 17283 & 12480 & 11476 & 15985 & 17573 & 9035 & 10803 & 13458 & 11782 \\
\hline 5 & 18322 & 13741 & 4145 & 7266 & 8954 & 8490 & 14725 & 14516 & 13495 \\
\hline 6 & 13665 & 8929 & 15059 & 14885 & 16112 & 14151 & 12081 & 8070 & 15750 \\
\hline 7 & 11619 & 12009 & 5416 & 8096 & 9293 & 10381 & 13188 & 11084 & 13905 \\
\hline 8 & 12623 & 10308 & 9893 & 10768 & 6193 & 11319 & 15500 & 9121 & 14814 \\
\hline 9 & 14351 & 8958 & 7757 & 10139 & 8294 & 10589 & 10836 & 12987 & 13143 \\
\hline 10 & 18791 & 16422 & 11701 & 8201 & 14830 & 12651 & 13873 & & 12744 \\
\hline $\begin{array}{l}\text { Mean AUC } \\
(0-24)\end{array}$ & 14508 & 11771 & 9641 & 11882 & 12907 & 11269 & 12853 & 11478 & 12790 \\
\hline $\begin{array}{l}\text { Standard } \\
\text { Deviation }\end{array}$ & 3563 & 2339 & 3195 & 3195 & 4349 & 2302 & 2649 & 2057 & 1892 \\
\hline
\end{tabular}




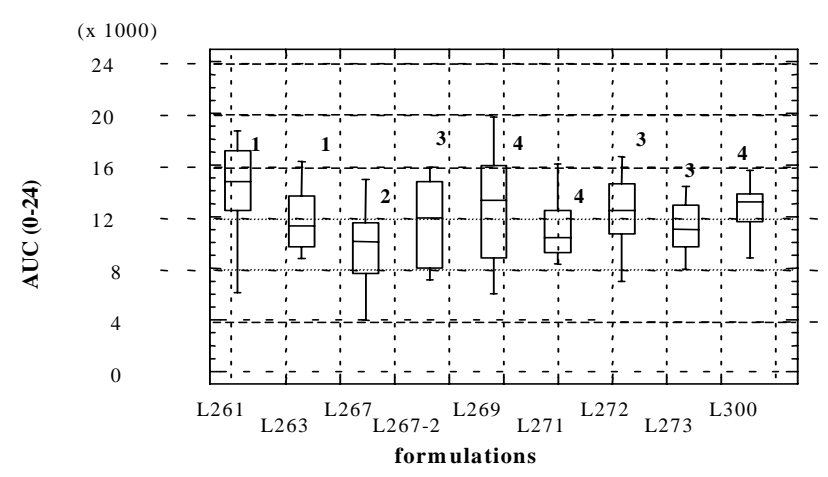

Fig. 1. Box-and-Whisker Plot for $\mathrm{AUC}(0-24)$ of formulations L261-L300

Another statistical method, multiple range analysis, requires suitable criterion to be used for specific case. The Least Significant Difference (see Table 3) method provided the most discriminating power in this case and confirmed the significant difference of L261 and L 267 formulations as well as that of formulations L267 - L269, L267 - L272, and L267 - L300. The Tukey HSD and Bonferroni methods identified only the formulations L261 and L 267 as different. The Scheffé method did not found any pair of formulations significantly different from the point of $\mathrm{AUC}(0-24)$.

\section{Particle size determination}

The distribution of particle sizes of individual formulations is given in Table 4 . These data were processed by Principal Component Analysis. As can be seen from Figure 2, more than $54 \%$ of the variability in data can be explained by one principal component and other $26 \%$ of variability by the second principal component. Other components 3, 4, 5, 6 and 7 contribute to the description of variability in data by additional $8 \%, 5 \%$, $3 \%, 2 \%$ and $1 \%$, respectively.

It can be concluded that the major part of variability in data $(>80 \%)$ can be explained by components 1 and 2.

When the information contained in each particle size distribution spectrum is described by two principal components only, the 9 formulations can be divided into 4 different groups of formulations having similar particle size distribution within group and different particle size distribution between groups. The situation is graphically shown in Figure 3. Group I includes formulations L261 and L263 (see also Fig. 4), Group II consists of one formulation L267 (see Fig. 5), Group III includes formulations L267.2, L272, and L273 (see also Figure 6), and Group IV includes formulations L269, L271 and L300 (see Fig. 7).

Table 3. Multiple Range Analysis of Bioavailability Results of 9 Tested Formulations L261 - L300

\begin{tabular}{|c|c|c|c|c|}
\hline \multirow[t]{2}{*}{ Method } & Contrasts & \multirow[t]{2}{*}{ Difference } & \multirow[t]{2}{*}{ +/- Limits } & \multirow{2}{*}{$\begin{array}{l}\text { Significant } \\
\text { Difference }\end{array}$} \\
\hline & $\begin{array}{l}\text { (pairs of samples } \\
\text { compared) }\end{array}$ & & & \\
\hline \multirow{5}{*}{$\begin{array}{l}\text { LSD method (Least } \\
\text { Significant } \\
\text { Difference) }\end{array}$} & L261 - L267 & 4867.45 & 2771.66 & $*$ \\
\hline & L261 - L271 & 3239.15 & 2771.66 & $*$ \\
\hline & L267 - L269 & -3265.95 & 2771.66 & $*$ \\
\hline & L267 - L272 & -3005.70 & 2771.66 & $*$ \\
\hline & L267 - L300 & -3149.55 & 2771.66 & $*$ \\
\hline $\begin{array}{l}\text { Tukey HSD } \\
\text { (Honest Signifi-cant } \\
\text { Difference) }\end{array}$ & L261 - L271 & 4867.45 & 4439.68 & $*$ \\
\hline Bonferroni & L261 - L271 & 4867.45 & 4613.15 & $*$ \\
\hline Scheffe & none & - & - & - \\
\hline
\end{tabular}

\footnotetext{
* denotes a statistically significant difference
} 
Table 4. Distributions of Particle Size of 9 Different Formulations L261 - L300

\begin{tabular}{|c|c|c|c|c|c|c|c|c|c|c|}
\hline \multirow[b]{2}{*}{$\begin{array}{l}\text { Particle } \\
\text { Size }[\mathrm{nm}]\end{array}$} & \multirow[b]{2}{*}{$\begin{array}{l}\text { variable } \\
\text { name }\end{array}$} & \multicolumn{9}{|c|}{ Particle count [Relative Intensity Units] } \\
\hline & & L261 & L263 & L267.2 & $L 267$ & L269 & L.271 & $\mathbf{L} 272$ & $\mathbf{L 2 7 3}$ & L300 \\
\hline 5 & $\mathrm{x} 1$ & 0 & & 0 & $\mathbf{0}$ & 0 & 0 & 21 & $\overline{0}$ & \\
\hline 6 & $x_{2}$ & 0 & & 0 & 0 & 0 & 0 & 31 & 0 & 0 \\
\hline 7 & $x^{3}$ & 0 & & 0 & 0 & 0 & 0 & 45 & 0 & 0 \\
\hline 8 & $\mathrm{X} 4$ & 0 & & ; & 0 & 0 & 0 & 60 & 0 & \\
\hline 9 & $\mathrm{x} 5$ & 0 & & ; & $\mathbf{0}$ & 0 & 0 & 75 & $\frac{0}{0}$ & 0 \\
\hline 10 & $x_{6}$ & 0 & & 0 & 0 & 0 & 0 & 88 & 0 & 0 \\
\hline 11 & $\mathrm{x} 7$ & 0 & & o: & 0 & 0 & 0 & 97 & 34 & 0 \\
\hline 12 & $x 8$ & 0 & & 0 & 0 & 0 & 0 & 99 & 48 & \\
\hline 13 & $\times 9$ & 0 & & 0 & 0 & 0 & 0 & 100 & 62 & 0 \\
\hline 14 & $\times 10$ & 0 & & 0 & 0 & 0 & 0 & 99 & 75 & \\
\hline 15 & $x_{11}$ & 0 & & 0 & 13 & 0 & 0 & 97 & 89 & 0 \\
\hline 16 & $\times 12$ & 0 & & 0 & 26 & 0 & 0 & 92 & 94 & 0 \\
\hline 17 & $X 13$ & 0 & & 10 & 39 & 5 & 0 & 88 & 100 & 0 \\
\hline 18 & $\mathrm{X} 14$ & 0 & & 9 & 52 & 19 & 0 & 84 & 96 & 0 \\
\hline 19 & $\times 15$ & 0 & & 0 & 65 & 33 & 0 & 80 & 92 & 0 \\
\hline 20 & $\times 16$ & 0 & & 0 & 79 & 47 & 0 & 75 & 89 & 0 \\
\hline 25 & $x \uparrow 7$ & 0 & & 0 & 100 & 61 & 88 & 45 & 48 & \\
\hline 30 & $x+8$ & 0 & 2 & 9 & 79 & 89 & 100 & 31 & 23 & 20 \\
\hline 35 & $\mathrm{X} 19$ & 0 & & 0 & 39 & 100 & $\mathbf{8 8}$ & 21 & 0 & 25 \\
\hline 40 & $\times 20$ & 0 & & 0 & 26 & 89 & 61 & 13 & 0 & 22 \\
\hline 45 & $\times 21$ & 0 & & 0 & 13 & 75 & 33 & 7 & 0 & 17 \\
\hline 50 & $\times 22$ & 0 & & 0 & 0 & 61 & 0 & 3 & 0 & \\
\hline 60 & $\times 23$ & 0 & & o & 0 & 33 & 0 & 0 & 0 & \\
\hline 70 & $\times 24$ & 0 & & 0 & 0 & 0 & 0 & 0 & 0 & \\
\hline 80 & $\times 25$ & 0 & & 0 & 0 & 0 & 0 & 6 & 0 & \\
\hline 90 & $\times 26$ & 0 & & 0 & 0 & 0 & 0 & 9 & 0 & 0 \\
\hline 100 & $\times 27$ & 0 & & 0 & 0 & 0 & 0 & 11 & 5 & \\
\hline 150 & $\times 28$ & 0 & & 0 & 0 & 0 & 0 & 25 & 7 & \\
\hline 200 & $\times 29$ & 22 & & 0 & 0 & 0 & 13 & 17 & 4 & \\
\hline 250 & $\times 30$ & 100 & & 0 & 0 & 10 & 15 & 5 & 0 & 0 \\
\hline 300 & X31 & 22 & & 0 & 0 & 12 & 13 & 0 & 0 & \\
\hline 350 & $\times 32$ & 0 & 2 & 8 & 0 & 10 & 8 & 0 & 0 & \\
\hline 400 & X33 & 0 & 5 & 3 & 0 & 0 & 0 & 0 & 0 & \\
\hline 450 & $\times 34$ & 0 & 7 & 8 & 0 & 0 & 0 & 0 & 0 & 0 \\
\hline 500 & X35 & 0 & 7 & 8 & 0 & 0 & 0 & 0 & 0 & \\
\hline 600 & $\times 36$ & 0 & 2 & 8 & 0 & 0 & 0 & 0 & 0 & 0 \\
\hline 700 & $\times 37$ & 0 & & 0 & 0 & 0 & 0 & 0 & 0 & \\
\hline 800 & $\times 38$ & 0 & & 0 & 0 & 0 & 0 & 0 & 0 & 0 \\
\hline 800 & $\times 39$ & 0 & & 0 & 0 & 0 & 0 & 0 & 0 & 0 \\
\hline 1000 & $\times 40$ & 0 & & 0 & 0 & 0 & 0 & 0 & 0 & 0 \\
\hline
\end{tabular}

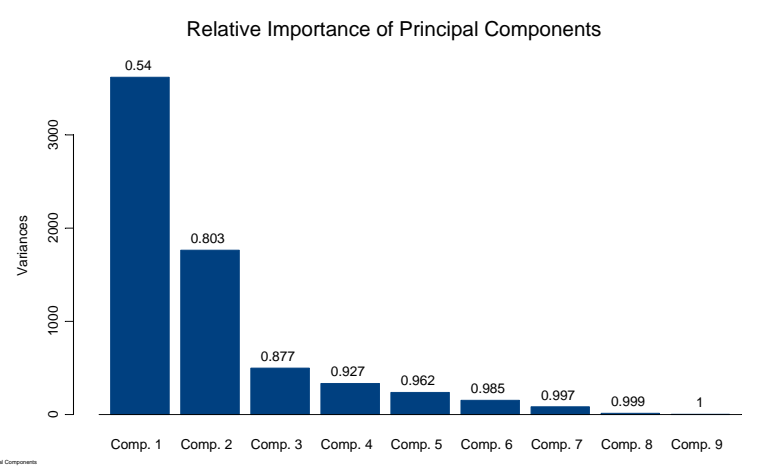

Fig. 2. Principal component analysis of Particle Size Distribution

Groups I, III and IV are substantially different from each other from the point of particle size distribution. On the other hand, formulations being within the same group cannot be considered different but rather similar with respect to the distribution of particle sizes.

Another statistical method which was used for evaluation of the similarity or dissimilarity of particle size distributions is the cluster analysis. As can be seen from Figure 8, the formulations L261, L 263 and L300 are classified as related (similar) formulations, as well as the formulations L267.2, L272, and L273. At the same time, these two groups are relatively distant and substantially different from one another. Group IV includes formulations L269 and L 271, and also formulation L267 which was evaluated as a self-standing group by PCA method.

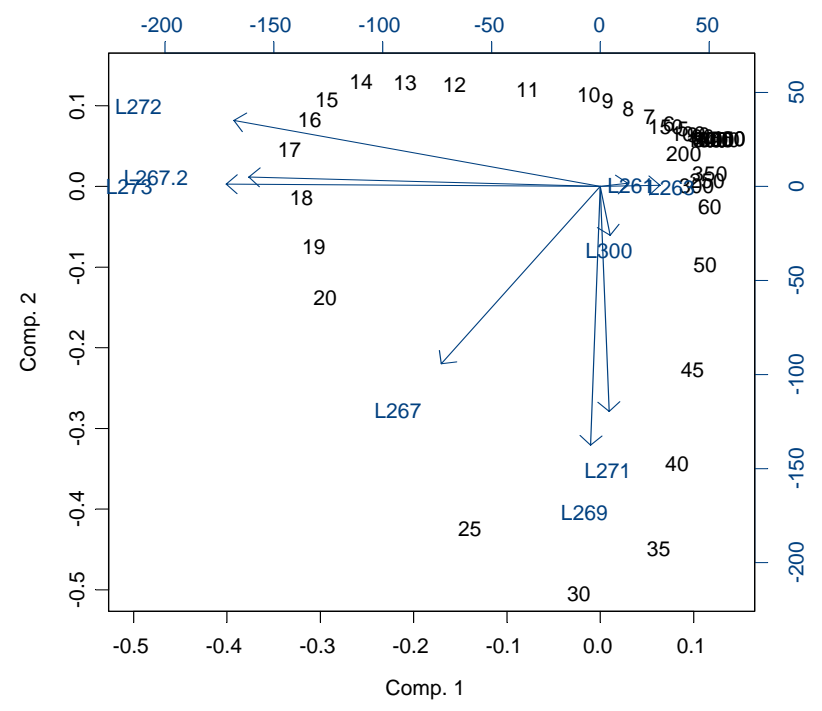

Fig. 3. Principal component analysis of Particle Size Distribution of 9 Different Formulations - Analysis by Two Components
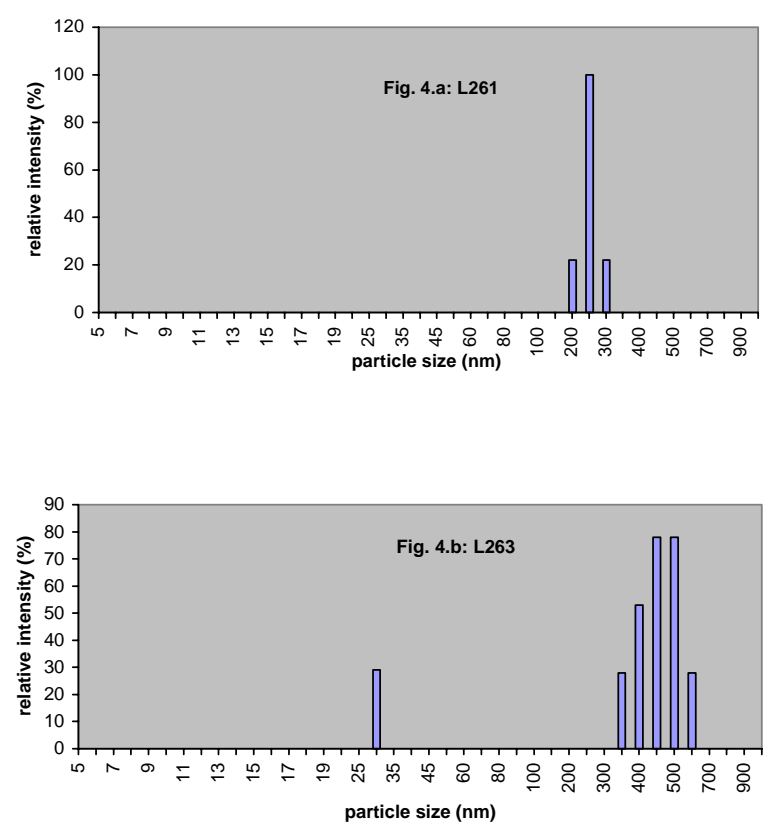

Fig. 4. (a, b) Particle Size Distribution of Formulations L261 and L263 resolved as similar by PCA method - Group I 


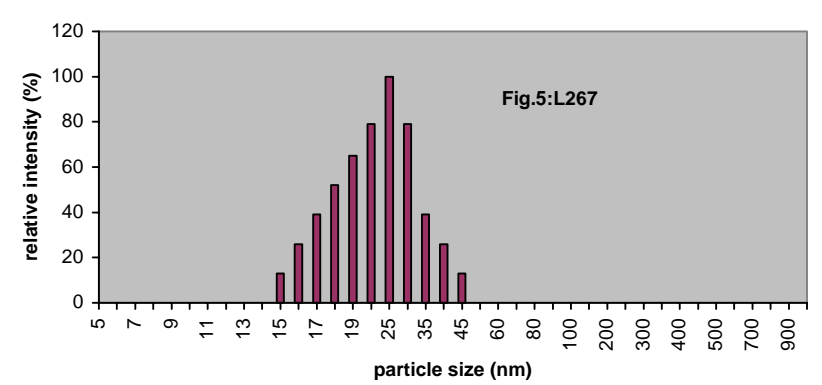

Fig. 5. Particle Size Distribution of Formulation L267 - Group II
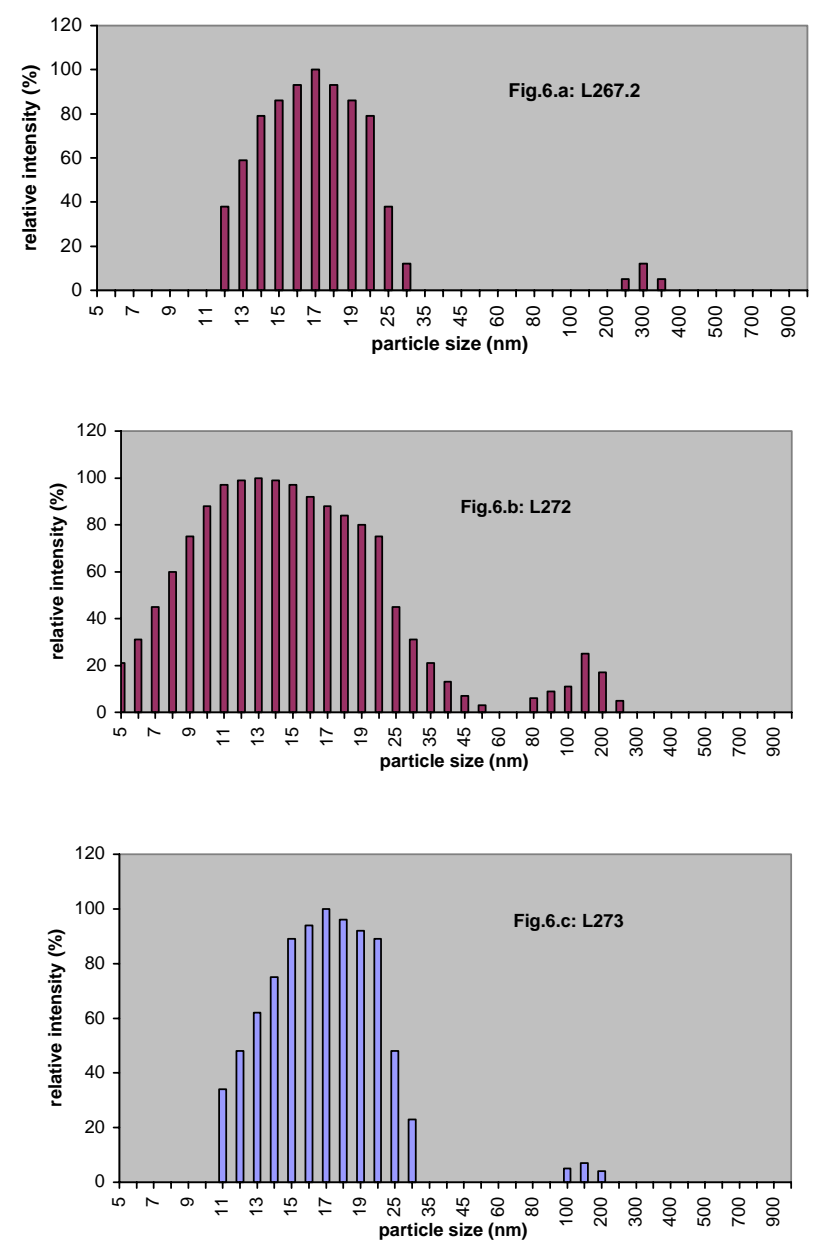

Fig. 6. (a, b, c) Particle Size Distribution of Formulations L267.2, 272 and L273 resolved as similar by PCA method - Group III
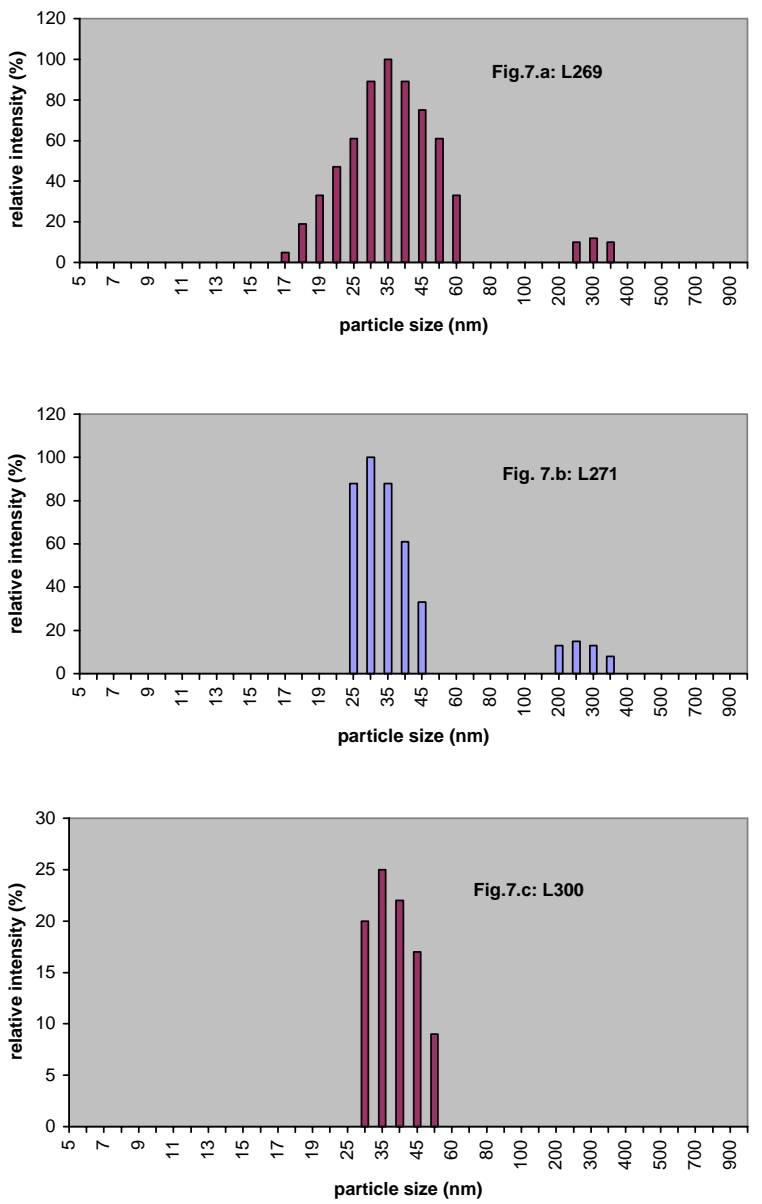

Fig. 7. (a, b, c) Particle Size Distribution of Formulation L269, L271 and L300 resolved as similar by PCA method - Group IV

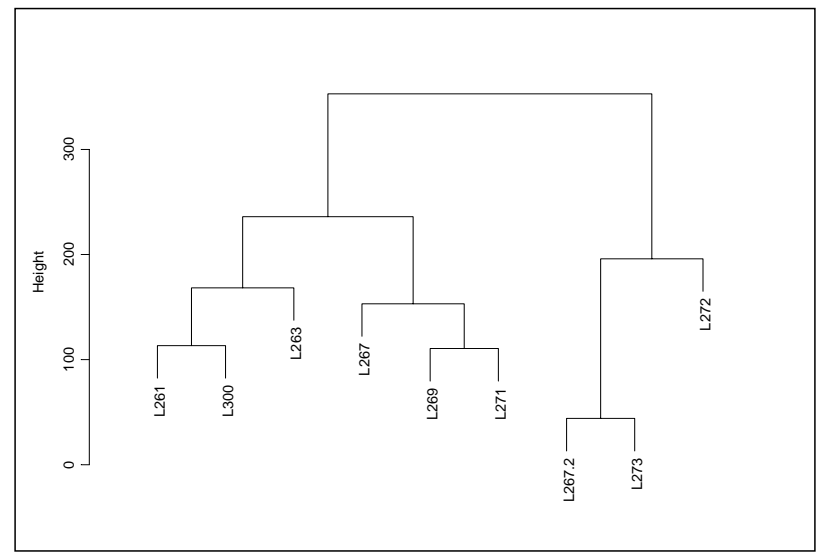

Fig. 8. Cluster Analysis of Particle Size Distribution of 9 Different Formulations 


\section{DISCUSSION}

Which is concerning the results of multiple comparisons, the Scheffé method (7) produces the widest interval statements and thus it is the most conservative. For this purpose, the Tukey method (8) seems to be the most suitable. The same result provides the Bonferroni method. Therefore, we consider the bioavailability of formulations L261 and L267 to be significantly different, the bioavailabilty of L261 to be significantly higher than that of L267. Surprisingly, the formulation L261 forms one of the largest particles (similarly as L263), and the formulation L267 forms very fine particles having maximum particle count around $25 \mathrm{~nm}$.

Formulations L267.2, L 269, L271, L272, L273 and L300 are all highly bioavailable, their average AUC $(0-24)$ lies in the range $10,000-14,000 \mu \mathrm{g} / \mathrm{l} . \mathrm{h}$. If we look at their particle size distribution, formulations L267.2, L272, and L273 are classified as different from formulations L269, L271 and L300. However, all of them have maximum particle count for particles in the range from 10 to $50 \mathrm{~nm}$, so from practical point of view, the differences in particle sizes in this range can hardly tell something about their effect on absorption and bioavailability.

Vice versa, the maximum difference in particle size was observed for the formulation L272 on one side (it forms the smallest particles) and formulations L261 and L263 on the other side (they form the largest particles). If we look at their bioavailability, there is no significant difference between these two groups, as the AUC (0-24) of the L272 formulations is in between the formulations L261 and L263. From these data, it seems that particle size is not the key characteristic which affects the bioavailability, and that it is possible to prepare highly bioavailable formulations for cyclosporine active substance which do not necessarily have to form very fine particles, as for example microemulsion (particle size $<200 \mathrm{~nm}$ ).

When particle size is not the key factor, a question arises what other characteristic can explain for the differences in absorption and bioavailability of different cyclosporine A formulations. One of the possible explanations is that the actual contact surface can be the answer to this question. It can explain both for the fact why some experiments showed that the reduction of particle size led to an enhancement of absorption of cyclosporine A, as well as for the fact why some formulations are highly bioavailable even though they form very large particles in solution. In our opinion, the reason for high absorption of some large particles forming formulation lies in the deformation and/or adhesive characteristics of such particles, which are able to produce much larger effective contact surface at the epithelial layer than would correspond to their approximation by ideal spherical shape.

\section{CONCLUSION}

We have proved that it is possible to prepare different formulations with cyclosporine A which have different particle size distribution but the same or similar bioavailability in dogs. According to our results, in the submicron region, the particle size distribution of formulations based on self-emulsifying drug-delivery systems does not explain for the differences in bioavailability and is not the key characteristics which has to be observed when formulating the self-emulsifying drug delivery system. It is suggested that a more suitable, bioavailability-related formulation feature has to be found out which can fulfil the role.

\section{ACKNOWLEDGEMENTS}

The authors would like to thank to Mr. M. Pisárčik, Department of Chemical Theory of Drugs, Faculty of Pharmacy, Commenius University, Bratislava, Slovak Republic, for his contribution related to the particle size measurement, and to prof. M. Meloun, Department of Analytical Chemistry, Technical University Pardubice, Czech Republic for his valuable comments on statistical evaluation.

\section{REFERENCES}

1. Behrens, D., Fricker, R., Bodoky, A., Drewe, J., Harder, F., Heberer, M. (1996) Comparison of cyclosporin A absorption from LCT and MCT solutions following intrajejunal administration in conscious dogs. J. Pharm. Sci. 85(6), 666-8.

2. Lerk, P. C., Sucker, H. (1993) Application of sucrose laurate in topical preparations of cyclosporine A. Int. J. Pharm. 92, 197-202.

3. Choice, E., Masin, D., Bally, M. B., Meloche, M., Madden, T. D. (1995) Liposomal cyclosporine. Comparison of drug and lipid carrier pharmacokinetics and biodistribution. Transplantation 60(9), 1006-11.

4. Ouyang, C., Choice, E., Holland, J., Meloche, M., Madden, T. D. (1995) Liposomal cyclosporine. Characterization of drug incorporation and interbilayer exchange. Transplantation 60(9), 999-1006.

5. Andrýsek, T. (2000) Development of cyclosporine containing dosage forms. Thesis, Pharmaceutical Faculty, Commenius University, Bratislava (in Czech language).

6. Hutchinson, K. G., MacGregor, K., Embleton, J. K., Seager, H., Solomon, L. J. and Pouton, C. W. (1995) Optimizing the gastrointestinal absorbtion of hydrophobic drugs using micro-emulsions and other liquid formulations; in Formulation of poorly available drugs for oral administration (Couvreur P., Duchene D., Kalles I., ed.), Editions de Santé, Paris; 121-125.

7. Scheffé, H. (1953) A method for judging all contrasts in the analysis of variance. Biometrika, 40, 87.

8. Tukey, J. W. (1949) Comparing individual means in the analysis of variance. Biometrics, 5, 99. 